These strong protests had the desired effect for the time being, and it was not till 1853 that another attempt was made to bring a railway within the Park. This was by the South-Eastern Company, and being postponed for a year, was not heard of again. In I863, however, the London, Chatham, and Dover Company proposed a line from Dulwich to Epsom passing within 700 feet of the Observatory; and the South London, Greenwich, and Woolwich Railway another passing within 600 feet. Sir George Airy was at first inclined to think that, if these railways were laid in tunnels, they might be permitted. But as facilities for making experiments had meantime increased with the multiplicity of lines, he renewed his investigations at the suggestion of the Hydrographer, and found that the protection of the tunnel was by no means established; and in other respects he had been if anything too lenient in assigning minimum distances. His conclusions from the experiments were :-

"I. It is indispensable that the railway pass through the Park in a covered tunnel.

"II. It is indispensable that its minimum distance from the transit circle of the Royal Observatory exceed 1000 feet."

The result of all these independent experiments seem to be that even with small instruments, such as a sextant or a small telescope, vibration is sensible at 1000 feet distance; and that though a tunnel may be a protection in some cases (we shall presently find reason to question this more seriously) the reasons are not sufficiently understood to enable us to predict the influence of individual tunnels. All the observations, except one of Dr. Robinson's, have reference to reflection observations; but it does not follow that these are the only observations disturbed, as is made abundantly clear by the single observation of Dr. Robinson's referred to, where the telescope was practically shaken to another position against the clamp. It is in reflection observations that the vibration is most easily discernible, but errors introduced into other observations are no less serious because they are not readily detected. Observation with mercury is a delicate test, but it is quite possible that we may very soon find even a more delicate test necessary. We are, for instance, only on the threshold of photographic experiments for which the most perfect steadiness is essential; and it is of the utmost importance to make sure that our large Observatories are so protected as to be available for such work as is gathering shape in the mists of the near future. If any mistake has been made in dealing with railway proposals, it has been that of being too lenient ; firstly, from the desire to yield as far as possible in matters affecting public convenience; and, secondly, perhaps from not fully appreciating the remark of Captain Beaufort in 1835 , that the results obtained with small instruments must be properly magnified for dealing with large ones. This point has been made clear by the last case we shall quote, also from the history of the Royal Observatory. Proposals for an adjacent railway were renewed, as we have said above, in 1888 . It had been already noticed that the lines which had been permitted were not sufficiently remote to prevent disturbance, and accordingly experiments were now made with the transit circle itself instead of with a small instrument. An observer was stationed at the transit circle prepared for a nadir observation, and for an hour noted the times when the images were steady, when partially disturbed, and when so agitated as to prevent observation. These times were noted carefully by a standard clock to within a few seconds. Other observers were furnished with watches set to standard time, and travelling on the various lines of railway in the neighbourhood noted the exact times of stopping and starting of all trains, entries into tunnels, \&c. The observations were made near midnight when other traffic was stopped. On the following day the independent records of the transit circle observer and the train observers were compared. These operations were repeated on five separate nights. The result of the series of observations may be gathered from the following extract from the Report of the Astronomer-Royal to the Board of Visitors, 1888 June 2 :-

"It resulted from these experiments that trains on the Greenwich-Maze Hill Railway caused great disturbance during their passage, not only on the section between Greenwich and Maze Hill, the nearest point of which is 570 yards from the transit circle, but also on the line beyond Greenwich on the London side, and beyond Maze Hill on the Woolwich side. The distances of the Greenwich and Maze Hill Stations from the Observatory are about 970 and 670 yards respectively ... The disturbance was very great during the passage between Greenwich and Maze Hill, the reflected image being invisible while the train was in the tunnel, at a minimum distance of 570 yards, and there was considerable disturbance during the passage of trains through the Blackheath-Charlton tunnel, at a distance of a mile, the reflected image becoming occasionally invisible."

It thus appears that the tunnels increased rather than diminished the disturbance; and that the minimum distance for insensible tremor had been considerably underestimated. But the interference with the work of the Observatory is not serious. By the vigorous action of Sir George Airy and his successor the national Observatory has been saved from the misfortunes which have befallen Paris and Berlin, where traffic has been allowed to make certain classes of observation impossible.

\section{H. H. TURNER.}

\section{TITANOTHERIUM IN THE BRITISH MUSEUM.}

TO those English zoologists who have not had the good fortune to visit the palæontological museums of the United States the huge Miocene mammals forming the family Titanotheriidce have been hitherto known only by description and small-sized figures of the skull and skeleton, which, however excellent they may be, afford but a very inadequate idea of the proportions of these most remarkable Perissodactyle Ungulates. Recently, however, Prof. O. C. Marsh, of New Haven, to whose generosity our National Museum is already much indebted, has presented that institution with a beautifully executed model of the skull of one of these mighty brutes, which is now exhibited in the front palæontological gallery, below the head of the skeleton of the Kentucky mastodon. By singular good fortune the Keeper of the Geological Department of the Museum has been enabled at the same time to purchase associated examples of the teeth of another member of the family, which are placed alongside of the cast, and thus enable us to see the actual state of preservation in which the remains of these creatures are found.

The Titanotheriide were first made known to science from the evidence of specimens of the dentition described years ago by the French naturalist Pomel, by whom the name Menodus was proposed for their owner. Unluckily, however, this name was preoccupied by the earlier Menodon; and we are therefore compelled to adopt for the type member of the family the name Titanotherium, which is the first of the numerous terms proposed by American writers. The species of which the skull has been presented to the Museum is made by Prof. Marsh the type of a distinct genus under the name of Brontops. The chief distinction of this form from the type of Brontotherium, which seems inseparable from Titanotherium, appears to be the reduced number of incisors, but if writers like the Director of the Museum are right in regarding such variations in the allied group of the 
Rhinoceroses as of not more than specific importance, this species should be included in the type genus.

These Titanotherioids appear to have been most nearly allied to the Rhinoceroses among existing forms, as is at once apparent from the contour of the skull. According to Prof. Marsh they were larger than the Dinocerata of the Eocene, and nearly equalled in size the existing elephants. The skull differs from those of the rhinoceroses, however, in that instead of having one or two horns placed in the middle line of the nasal region and having no sort of bory connection with the skull itself, it has two large processes of solid bone in a transverse line immediately over the nose, which were probably invested with a horny sheath.

The molar teeth are, moreover, unlike those of the rhinoceroses, having excessively low crowns, and an arrangement of the tubercles and ridges very similar to that obtaining in the Tertiary genera Limnohyus and Chalicotherium; the first of which is certainly, and the latter probably, a Perissodactyle, although the recent dis-

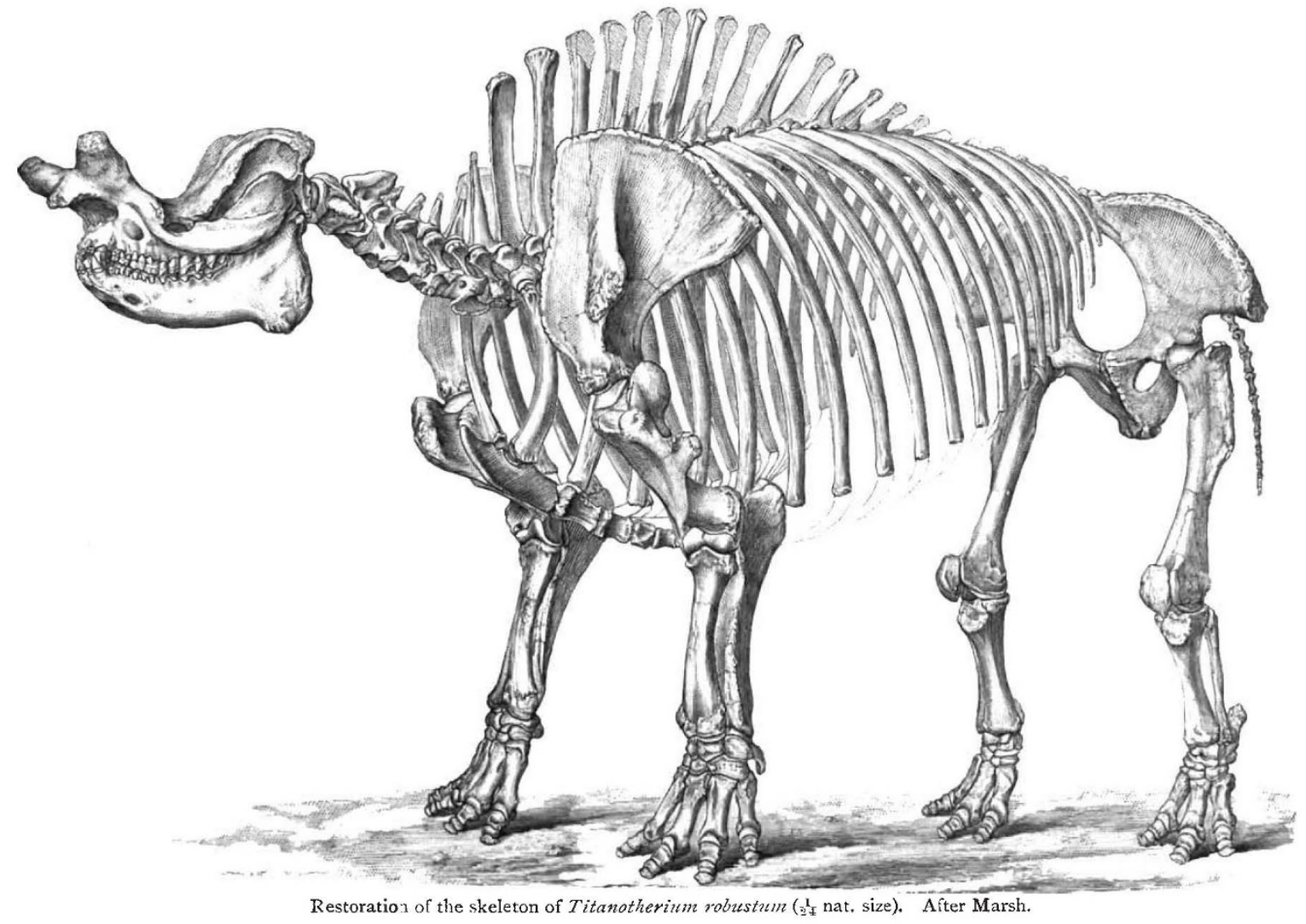

covery that the peculiar claws upon the evidence of which the supposed Edentate genus Macrotherium was founded are referable to it, render it a most aberrant type.

The skeleton to which the original of the cast presented to the Museum pertains was found in 1874 by the donor in those beds of the Dakota Miocene known as the Brontotherium beds, and it appears to be the best preserved example yet known. A restoration is given in the accompanying woodcut. According to Prof. Marsh

\section{NOTES.}

THERE is some talk of a Committee of the Royal Society being appointed to investigate the subject of colour-blindness, and the proper methods of testing the colour-vision of employés on railways.

WE may remind our readers that all applications for assignments from the Government Grant must be sent to the Assistant Secretary of the Royal Society on or before the last day of February. Applications received after that date will not be considered by the Committee of this year.

AN influential Committee has been formed for the purpose of securing that the scientific and other friends of the late Dr. these deposits are several hundred feet in thickness, and may be separated into horizons, characterized by peculiar species of Titanotheriide. The remains of several hundred individuals of this exclusively American group have already been secured by the palæontologists of $\mathrm{New}$ Haven, and their English confrères look forward to the publication of the sumptuous monograph in which Prof. Marsh promises to illustrate these specimens with much interest.

McNab, Professor of Botany in the Royal College of Science, Dublin, shall have an opportunity of expressing their appreciation of his work and their respect for his memory. Through no fault of his own, Prof. $\mathrm{McNab}$ was unable to make adequate provision for his wife and five children; and it is proposed that the memorial shall consist of a fund, sufficiently large to be of real service to his family. A good many subscriptions have already been received or promised, and we hope that many more may be forthcoming. Mr. Greenwood Pim, Easton Lodge, Monkstown, Co. Dublin, acts as hon. secretary; Prof. W. N. Hartley, F.R.S., Royal College of Scieñce, Dublin, as hon. treasurer. As Prof. Hartley has been obliged to leave Dublin for some time, all communications should be addressed, and cheques made payable, to the hon. secretary. 